\title{
AVALIAÇÃO DE PASSIVO AMBIENTAL EM SOLO E ÁGUA SUBTERRÂNEA EM ÁREA DE ARMAZENAMENTO DE COMBUSTÍVEIS
}

\author{
Marilia Offemann Skowronski ${ }^{1}$; Márcio Roberto Schneider ${ }^{2}$; Pablo Heleno Sezerino ${ }^{3}$ \& Henry \\ Xavier Corseuil ${ }^{4}$
}

\begin{abstract}
Resumo - A contaminação do solo e das águas subterrâneas por derramamentos de petróleo e derivados é um problema que vem ganhando grande importância no Brasil nos últimos anos em função do aumento do número de áreas impactadas. Em resposta ao problema, os órgãos de controle ambientais nacionais estão intensificando o foco sobre a contaminação de solos e águas subterrâneas, criando instrumentos legais como as Resoluções CONAMA nº 396/2008 e 420/2009. A partir destas determinações a Associação Brasileira de Normas Técnicas (ABNT) criou uma série de normas a fim de orientar e detalhar o processo de avaliação de passivos ambientais e o gerenciamento de áreas contaminadas. A motivação deste trabalho foi demonstrar a aplicação das normas da $\mathrm{ABNT}$ no gerenciamento de uma área contaminada, pois ainda constam poucos trabalhos técnicos que ilustrem e exemplifiquem a utilização das mesmas, principalmente em casos com cenários de contaminação complexos e diversificados, como objeto de estudo deste trabalho que foi um terminal de armazenamento de combustíveis. Realizou-se uma pesquisa bibliográfica dos estudos ambientais pretéritos da área de interesse a fim de obter informações para elaborar o modelo conceitual. Com base neste modelo, estabeleceram-se as estratégias de gerenciamento ambiental para cada uma das 12 subáreas do terminal, tais como avaliação preliminar, investigação confirmatória, investigação detalhada, remediação e monitoramento.
\end{abstract}

Palavras-Chave - Gerenciamento ambiental, normas técnicas, passivos ambientais.

\begin{abstract}
The contamination of soil and groundwater by oil and oil spills is an issue that has gained great importance in Brazil in the past years due to the increase in the number of impacted areas. In response to the problem, the national environmental control agencies are intensifying the focus on the contamination of soil and groundwater, creating legal instruments as CONAMA Resolutions 396/2008 and 420/2009. From these determinations, the Brazilian Association of Technical Standards (ABNT) created a series of standards to guide and detail the process of evaluation of environmental liabilities and the management of contaminated areas. The motivation of this work was to demonstrate the application of the ABNT standards in managing a contaminated area, since there is only a few technical works that illustrate and exemplify the utilization of the same, especially in cases with complex and diverse contamination scenarios, as the object of study of the present work was a fuel storage terminal. A literature review of past environmental studies of the area of interest was conducted in order to get information to develop the conceptual model. Based on this conceptual model, was determined an environmental management strategies for each of the 12 sub-areas of the terminal, such as preliminary assessment, confirmatory investigation, detailed investigation, remediation and monitoring.
\end{abstract}

Keywords - Environmental management, technical standards, environmental liabilities.

\footnotetext{
${ }^{1}$ Universidade Federal de Santa Catarina - UFSC, Centro Tecnológico - CTC, Departamento de Engenharia Sanitária e Ambiental, Laboratório REMA. Florianópolis/SC. CEP: 88040-900. Fone: (48) 3721- 2132

${ }^{2}$ E-mail: mariliaesa@ @otmail.com

${ }^{3}$ E-mail: mrs2007@hotmail.com

${ }^{4}$ E-mail: pablo.sezerino@ufsc.br

${ }^{5}$ E-mail: henry.corseuil@ufsc.br
} 


\section{1 - INTRODUÇÃO}

A contaminação do solo e das águas subterrâneas por derramamentos de petróleo e derivados é um problema que vem ganhando grande importância no Brasil nos últimos anos em função do aumento do número de áreas impactadas. Os terminais de petróleo e derivados lidam diariamente com a possibilidade de ocorrência de derrames acidentais inerentes às operações de armazenamento de produtos. Na maioria dos casos, os derramamentos têm origem na rede de dutos de distribuição e tanques de armazenamento. O rompimento de dutos que transportam dezenas de metros cúbicos de petróleo por dia, e o vazamento nos tanques de armazenamento em terminais, podem liberar no meio ambiente, quantidades significativas de petróleo e seus derivados, podendo causar a contaminação do solo, água e ar (PEDROZO et al, 2002).

Ao longo dos últimos anos os órgãos de controle ambientais nacionais estão intensificando o foco sobre o problema da contaminação de solos e águas subterrâneas. A Companhia Estadual de Tecnologia de Saneamento Ambiental do Estado de São Paulo (CETESB) é um dos órgãos de controle ambiental que dispõe de informações detalhadas sobre áreas impactadas, como resultado da aplicação de um programa efetivo de cadastramento. Levantamentos disponibilizados pela CETESB (2013) indicam que entre os principais grupos de contaminantes de áreas contaminadas, destacam-se os solventes aromáticos, combustíveis líquidos, PAH, metais e solventes halogenados.

Diversos marcos legais importantes tangem direta ou indiretamente o controle da poluição dos solos e das águas subterrâneas no Brasil. O instrumento precursor das diretrizes ambientais no país é a Política Nacional do Meio Ambiente, instituída pela Lei no 6.938/81 (BRASIL, 1981), a qual estabelece a avaliação de impactos ambientais como um instrumento dessa lei, por meio da Resolução CONAMA nº 001/86 (CONAMA, 1986). Desta forma, todos os empreendimentos potencialmente poluidores, passaram a ter necessidade de obter o licenciamento ambiental para exercer suas atividades. Após a Resolução CONAMA nº 001/86 foi criada a Resolução CONAMA n²37/97 (CONAMA, 1997), a qual revisou e complementou os procedimentos e critérios utilizados para o licenciamento ambiental.

Com foco específico sobre o controle da poluição do solo e das águas subterrâneas, foram criadas as Resoluções CONAMA n 396/2008 e 420/2009. A Resolução CONAMA 396/2008 (CONAMA, 2008) dispõe sobre a classificação e diretrizes ambientais para o enquadramento das águas subterrâneas. A Resolução CONAMA 420/2009 (CONAMA, 2008) dispõe sobre critérios e valores orientadores e também sobre diretrizes para o gerenciamento ambiental de áreas contaminadas. Os órgãos ambientais estão intensificando as exigências sobre a avaliação de passivos ambientais em solos e águas subterrâneas como um requisito para obtenção das licenças 
prévia, de instalação e operação. A partir destas orientações do CONAMA, nos últimos anos, a Associação Brasileira de Normas Técnicas (ABNT) criou uma série de normas a fim de orientar e detalhar o processo de avaliação de passivos ambientais e o gerenciamento de áreas contaminadas.

A motivação deste trabalho foi demonstrar a aplicação das normas da ABNT no gerenciamento de uma área contaminada, pois ainda constam poucos trabalhos técnicos que ilustrem e exemplifiquem a utilização das mesmas, principalmente em casos com cenários de contaminação complexos e diversificados, como objeto de estudo deste trabalho.

\section{2 - OBJETIVOS}

\section{1 - Objetivo Geral}

Estabelecer estratégias para avaliar o passivo ambiental em uma área de armazenamento de combustíveis e definir ações de gerenciamento da área contaminada para o solo e águas subterrâneas de acordo com as especificações das normas técnicas brasileiras e das diretrizes da Resolução CONAMA n 420/2009.

\section{2 - Objetivos Específicos}

a) Com base em dados de investigações ambientais pretéritas, es-tabelecer o modelo conceitual (ABNT NBR 16.210/2013) para a área objeto do estudo de caso, para definição do problema;

b) Aplicação das normas técnicas brasileiras ABNT NBR 15.515-1/2007, 15.515-2/2011, 15.515-3/2013 e 16.210/2013 em uma área complexa, com múltiplos cenários de contaminação dife-rentes;

c) Apresentar as estratégias de gerenciamento ambiental para o controle de poluição da área de interesse, a fim de viabilizar a operação do empreendimento.

\section{3 - MATERIAIS E MÉTODOS}

\section{1 - Área de Estudo}

O cenário utilizado para a execução deste trabalho foi um terminal de armazenamento de combustíveis, que por razões de sigilo contratual não será informado o nome do terminal, assim como algumas informações referentes ao mesmo, como localização exata, coordenadas geográficas, empresas responsáveis, dentre outras. A caracterização e definição dos limites da área de interesse visa atender o conteúdo mínimo recomendado pela norma NBR 16.210/2013 para realização do modelo conceitual da área objeto de estudo deste trabalho. 
O terminal abrange uma área de aproximadamente $198.000 \mathrm{~m}^{2}$ e pode ser dividido em duas grandes áreas: área antiga (área do terminal), localizada no lado nordeste e área nova (área do píer), no lado sudoeste. Os limites da área de interesse abrangem uma região com ocupação predominante de indústrias, em que na direção nordeste há uma área residencial de pescadores e a leste um canal (ambiente marinho).

As instalações da área objeto de estudo, a qual armazena e distribui petróleo e seus derivados, estão divididas em área industrial e operacional/administrativa. A área industrial corresponde às áreas dos tanques de armazenamento, plataformas de abastecimento de caminhõestanque e vagões-tanque (desvio ferroviário), parque de bombas e oleodutos, além de área de depósito de resíduos. A área operacional e administrativa é constituída por laboratório, prédios administrativos, sala de operação, enfermaria, sala da engenharia, prédio do SMS (Saúde, Meio Ambiente e Segurança), prédio da engenharia, sala de manutenção. Junto à área do terminal encontram-se dois tanques aéreos de armazenamento.

Com base em ocorrências de contaminação identificadas em trabalhos anteriores, o terminal estudado neste trabalho foi dividido em 12 subáreas de interesse, de acordo com a Figura 1.

O desenvolvimento deste trabalho teve como base as seguintes etapas:

- Análise da legislação, resoluções e de normas técnicas brasileiras pertinentes ao presente trabalho.

- Levantamento de dados e obtenção das informações de investigações ambientais já realizadas na área de interesse, através de pesquisa bibliográfica.

- Pesquisa e compilação de dados para caracterizar a geologia e hidrogeologia local; pluviometria da região; substâncias químicas de interesse; cenários de contaminação; fontes de contaminação; e receptores e bens a proteger.

- Verificação da aplicabilidade das normas técnicas brasileiras ABNT NBR 15.515-1/2007, NBR 15.515-2/2011, NBR 15.515-3/2013 e NBR 16.210/2013.

- Definição de estratégias de gerenciamento ambiental de acordo com as normas técnicas da ABNT NBR 15.515-1/2007, NBR 15.515-2/2011, NBR 15.515-3/2013 e com a estrutura do gerenciamento de áreas contaminadas apresentada na Resolução CONAMA nº 420/2009.

\section{4- RESULTADOS E DISCUSSÃO}

\section{1 - Substâncias Químicas de Interesse}

As substâncias químicas de interesse devem ser identificadas segundo a NBR 16.2010/2013 (ABNT, 2013c) e também a possibilidade de ocorrência natural dessas substâncias. 
Com base no histórico das investigações ambientais realizadas na área, as substâncias químicas de interesse para cada meio, foram definidas a seguir:

Água subterrânea: MTBE, benzeno, xilenos, tolueno, etilbenzeno, TPH, naftaleno, alumínio, boro, chumbo, cobalto, ferro, manganês, mercúrio, níquel, prata, vanádio, zinco, nitrogênio amoniacal e sulfeto.

Solo: MTBE, benzeno, tolueno, etilbenzeno, xilenos, TPH, benzo(a)pireno, benzo(b)fluoranteno, dibenzo(a,h)antraceno, PAH, bário, cádmio, chumbo, cobalto, cobre, níquel e vanádio.

O sulfeto que foi identificado em diversas ocorrências está presente naturalmente nas águas subterrâneas, devido ao arraste de depósitos minerais contendo enxofre, resultado da decomposição da matéria orgânica, da redução de sulfatos por atividade bacteriana ou podendo estar relacionado a outros metais.

\section{2 - Geologia e Hidrogeologia Local}

A partir do Relatório Unificado de Diagnóstico Ambiental realizado em 2009, foi descrita a geologia local de acordo com os perfis de sondagens executados até 4,5 $\mathrm{m}$ de profundidade. Estes perfis revelaram, de modo geral, um horizonte inicial constituído de areia fina amarelada, variando de 0,0 a 1,5 $\mathrm{m}$ de profundidade, sobreposto a um pacote de areia fina cinza, por vezes, com lentes de areia fina argilosa cinza, variando de $1,0 \mathrm{~m}$ a 4,5 $\mathrm{m}$.

Determinou-se também através deste relatório a condutividade hidráulica média determinada para o terminal é de 2,25x10-3 cm/s, com mínima de 5,93×10-4 cm/s no PM-25 e máxima de 7,66x10-3 cm/s no PM-56. E também o gradiente hidráulico médio e a porosidade efetiva para o terminal foram estimadas em $0,62 \%$ e $33 \%$, respectivamente. Para estimativa da velocidade do escoamento subterrâneo, foi considerado valor da condutividade hidráulica igual a 2,25x10-3 cm/s. Com isso, a velocidade média estimada foi de 13,3 m/ano. 
Figura 1 - Delimitação das áreas de interesse do terminal.

\section{LEGENDA}

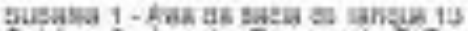

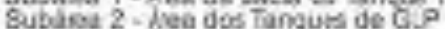

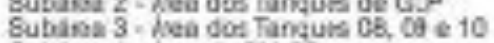

Subinar 3 - Kata dor Tang

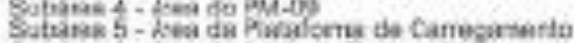

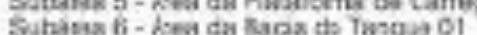

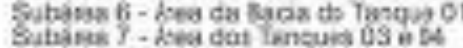

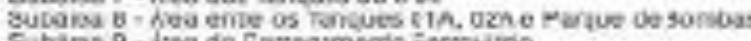

Subaras 9 - Nes do Caregameribo Ferrovirio

Subjas 10 Frea do Tosqua 06

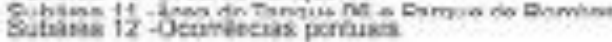

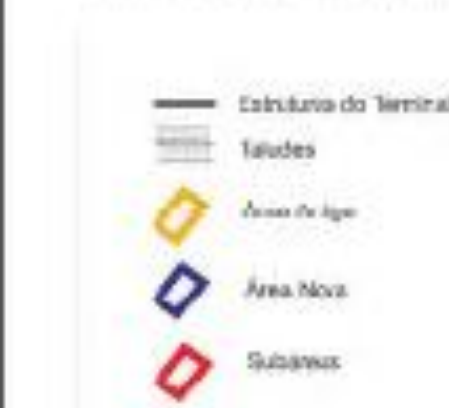




\section{3 - Pluviometria}

As variações do nível d'água do aquífero estão diretamente associadas à pluviometria, o que influencia também no comportamento da contaminação em fase livre e dissolvida, podendo alterar as espessuras de produto nos poços de monitoramento e as concentrações dos contaminantes em água subterrânea. Por este motivo é importante a apresentação dos índices pluviométricos, pois estes auxiliam na interpretação do comportamento dos contaminantes.

As informações de precipitação foram obtidas no sistema de informações hidrológicas da Agência Nacional de Águas (ANA, 2014) para uma estação localizada a aproximadamente a 4,5 km de distância do terminal. A área de interesse apresenta pluviometria média mensal de janeiro de 2007 a junho de 2014 de 93,8 mm e média anual para os anos de 2007 a 2013 de aproximadamente 1.100,0 mm por ano, com tendência a maiores volumes de chuva no final do verão e períodos mais secos nos meses de outubro e novembro.

\section{4 - Cenário de Contaminação}

De acordo com as investigações ambientais realizadas na área de interesse, será apresentado a seguir o cenário de contaminação, o qual compreende passivos ambientais em solo e água subterrânea. A definição deste cenário de contaminação servirá de base para elaborar ações de gerenciamento ambiental das áreas contaminadas do local.

No ano de 2012, foram realizados monitoramentos de fase livre na área de interesse do terminal e identificou-se 28 poços de monitoramento com presença de fase livre.

Com base nas campanhas de investigação realizadas foram mapeadas as seguintes áreas com presença de resíduo oleoso:

- $\quad$ Três focos de resíduo oleoso nas bacias dos tanques 01, 02 e 03;

- Existência de produtos oleosos na área limitada pelo tanque 04, tanques 01A, 02A e parque de bombas;

- Quatro focos de resíduo oleoso no entorno do tanque 05;

- Existência de resíduo oleoso na sondagem S-484, localizada ao lado do tanque de água;

- $\quad$ Presença de material oleoso nas proximidades dos tanques de GLP; e

- Nas bacias dos tanques 08, 09 e 10 foi mapeado um nível de areia cinza a preta com produtos sólidos secos.

As maiores concentrações de compostos orgânicos voláteis a $0,5 \mathrm{~m}$ de profundidade ocorreram: na área nas bacias de dois tanques; próximo à plataforma de carregamento; e próximo à enfermaria. Já as principais áreas impactadas por esses compostos a 1,0 $\mathrm{m}$ de profundidade localizam-se próximo às bacias de seis tanques. 
O monitoramento analítico mais recente de água subterrânea, realizado em outubro de 2011 não contemplou todos os poços localizados no terminal. Desta forma, para contemplar todos os poços monitorados, o cenário de contaminação em água subterrânea foi caracterizado por meio da unificação de vários monitoramentos analíticos.

\section{5 - Fontes Contaminação, receptores e bens a proteger}

O terminal é pavimentado com bloquetes de concreto nas proximidades do píer, com paralelepípedo nas áreas dos prédios administrativos e área de balança, concreto nas plataformas de carregamento e é sem pavimentação na área nova próximo aos limites do terreno e nas bacias de contenção dos tanques. Nos locais desprovidos de pavimento é possível o contato direto dos trabalhadores com o solo.

A presença de contaminação em solo superficial e subsuperficial por material oleoso bem como a presença de fases livre e dissolvida representam riscos aos trabalhadores comerciais/industriais que circulam na área, e aos trabalhadores de obras civis que venham a realizar obras de escavação na área. Cabe salientar que a via de exposição pela ingestão de água subterrânea não foi incluída no cenário de exposição, considerando que o abastecimento de água para da área objeto de estudo é proveniente de rede pública e, também, que os poços de captação identificados no entorno estão situados a $550 \mathrm{~m}$ do terminal, a montante deste. A Erro! Fonte de referência não encontrada. sintetiza o modelo conceitual para as fontes de contaminação, mecanismos de transporte, rotas de exposição e receptores para a área do terminal. São considerados como principais bens a proteger:

- Trabalhadores comerciais/industriais do terminal;

- Trabalhadores de obras civis, que venham a executar escavações na área;

- Trabalhadores comerciais/industriais de outras empresas vizinhas;

- Moradores da área residencial de pescadores, que são considerados conservadoramente, pois, estão localizados à montante do terminal. Esta área residencial está localizada a aproximadamente $300 \mathrm{~m}$ a nordeste do terminal; e

- $\quad$ Canal (ambiente marinho).

\section{6 - Estratégias de Gerenciamento ambiental}

Devido à área estudo de caso do terminal ser uma área complexa e com múltiplos cenários de contaminação distintos, fez-se necessária a divisão da mesma em subáreas, e conforme o modelo conceitual proposto baseado nas informações obtidas pelo modelo conceitual da NBR 16.210/2013. 
Para cada subárea a seguir, foram definidas as estratégias segundo as determinações da Resolução CONAMA no 420/2009 e orientações das normas NBR 15.515-1, NBR 15.515-2 e NBR 15.515-3.

Subárea 01: Elaborar um projeto detalhado de remediação e monitoramento periódico do sistema de remediação proposto.

Subárea 02: Investigação confirmatória para o produto oleoso no solo; investigação detalhada para água subterrânea; e avaliar a necessidade de realizar a avaliação de risco à saúde humana.

Subárea 03: Investigação confirmatória para o produto oleoso no solo; projeto básico de remediação para remoção da fase livre em água subterrânea; e avaliar a necessidade de realizar avaliação de risco.

Subárea 04: Investigação detalhada para solo e água subterrânea; se confirmada a fase livre com potencial de contaminação, elaborar projeto básico de remediação ou plano de intervenção; e avaliar a necessidade de realizar avaliação de risco.

Subárea 05: Investigação detalhada para água subterrânea e solo; e avaliar a necessidade de avaliação de risco.

Subárea 06: Implantação e operação do sistema emergencial de remediação, acompanhado dos monitoramentos periódicos da eficiência do sistema; investigação confirmatória para o produto oleoso no solo; e avaliar a necessidade de realizar avaliação de risco; se confirmada a contaminação no solo, elaborar o projeto de remediação para remoção do solo.

Subáreas 07, 08 e 10: Investigação confirmatória para o produto oleoso no solo; investigação detalhada para água subterrânea; se confirmada a contaminação no solo, elaborar o projeto de remediação para remoção do solo; e avaliar a necessidade de realizar avaliação de risco.

Subárea 09: Avaliação preliminar para fase livre; se confirmada a ocorrência de fase livre com potencial de contaminação, elaborar projeto básico de remediação ou plano de intervenção; e avaliar a necessidade de realizar avaliação de risco.

Subáreas 11 e 12: Investigação confirmatória para produto oleoso no solo; avaliação preliminar para fase livre; se confirmada a ocorrência de fase livre com potencial de contaminação, elaborar projeto básico de remediação ou plano de intervenção; avaliar a necessidade de realizar avaliação de risco. 


\section{5 - CONCLUSÃO}

Este trabalho teve como objetivo estabelecer estratégias para avaliar o passivo ambiental, tendo como objeto de estudo um terminal de armazenamento de combustíveis, definiu-se ações de gerenciamento da área contaminada para o solo e águas subterrâneas de acordo com as orientações das normas técnicas brasileiras e das diretrizes da Resolução CONAMA nº 420/2009.

Com a aplicação da norma técnica NBR 16.210/2013, foi estabelecido o modelo conceitual da área de interesse para definir os próximos passos da estratégia de avaliação de passivos ambientais em solo e água subterrânea em uma área de armazenamento de combustíveis, tomado como estudo de caso. A NBR 16.210/2013 estabelece orientações claras e precisas, mas não foi possível obter todas as informações necessárias para elaborar o modelo conceitual, uma vez que os relatórios elaborados pelas empresas de consultoria estavam incompletos. Por exemplo, alguns relatórios como o de escavação de trincheiras nos tanques 02, 03 e 05, relatório preliminar de investigação complementar não apresentaram os perfis de sondagens. Como o modelo conceitual proposto pela NBR 16210/2013 independe da etapa de gerenciamento ambiental em que a área se encontra o conteúdo mínimo a ser contemplado na elaboração do modelo conceitual pode sofrer alterações devido à ausência de informações completas, o que irá interferir na definição das ações de gerenciamento ambiental subsequentes.

Após a elaboração do modelo conceitual da área do Terminal, foram definidas as ações de gerenciamento ambiental seguindo as orientações das normas técnicas NBR 15.515-1/2007, 15.5152/2011 e 15.515-3/2013. As normas apresentam orientações detalhadas, porém, no estudo de caso, os estudos realizados por empresas de consultoria, os quais deveriam subsidiar o gerenciamento das áreas contaminadas, não contemplaram adequadamente todas as informações ambientais necessárias. Exemplos disso são as medições incompletas de parâmetros do solo e águas subterrâneas, lacunas no processo de monitoramento ambiental, problemas em análises químicas executadas fora dos padrões, entre outros problemas. Portando, mesmo sendo disponibilizadas orientações técnicas aos engenheiros e técnicos ambientais, é necessário que as empresas de consultoria ambiental se adequem às normas técnicas. Apesar das lacunas que dificultaram a definição de ações de gerenciamento da área de interesse, foram apresentadas recomendações de ações para suprir as lacunas encontradas nos diagnósticos ambientais. Desta forma, as estratégias de gerenciamento ambiental apresentadas para a área de interesse irão viabilizar a operação do terminal, uma vez que os riscos da contaminação existente serão minimizados por meio de ações intervenção, remediação e monitoramento, específicos a cada subárea do terminal. 


\section{6- REFERÊNCIAS BIBLIOGRÁFICAS}

AGÊNCIA NACIONAL DAS ÁGUAS. Banco de dados das estações pluviométricas. Disponível em: <http://www.hidroweb.ana.gov.br>. Acessado em: 24 out. 2014.

AGÊNCIA NACIONAL DO PETRÓLEO, GÁS NATURAL E BIOCOMBUSTÍVEIS. Glossário. Brasil, 2014. Disponível em: 〈http://www.anp.gov.br/?id=582\#t>. Acesso em: 18 nov. 2014.

AMORIM Jr, Carlos José. Avaliação dos Critérios de Impermeabilização de Bacias de Contenção da Norma ABNT NBR 17505-2/2006 para Terminais de Armazenamento de Petróleo e Derivados. Florianópolis, 2007. 114p. Dissertação (Mestrado) - Universidade Federal de Santa Catarina. Centro Tecnológico. Departamento de Engenharia Sanitária e Ambiental. Programa de Pós-Graduação em Engenharia Ambiental.

ASSOCIAÇÃO BRASILEIRA DE NORMAS TÉCNICAS. NBR 15.515-1: 2007. Passivo ambiental em solo e água subterrânea - Parte 1: Avaliação Preliminar. Rio de Janeiro, RJ, 2007. $47 \mathrm{p}$.

ASSOCIAÇÃO BRASILEIRA DE NORMAS TÉCNICAS. NBR 15.515-2: 2011. Passivo ambiental em solo e água subterrânea - Parte 2: Investigação Confirmatória. Rio de Janeiro, RJ, 2011. 19p.

ASSOCIAÇÃO BRASILEIRA DE NORMAS TÉCNICAS. NBR 15.515-3: 2013. Passivo ambiental em solo e água subterrânea - Parte 3: Investigação Detalhada. Rio de Janeiro, RJ, $2013 a$. $18 \mathrm{p}$.

ASSOCIAÇÃO BRASILEIRA DE NORMAS TÉCNICAS. NBR 16209: 2013. Avaliação de risco à saúde humana para fins de gerenciamento de áreas contaminadas. Rio de Janeiro, RJ, 2013b. 40p.

ASSOCIAÇÃO BRASILEIRA DE NORMAS TÉCNICAS. NBR 16210: 2013. Modelo conceitual no gerenciamento de áreas contaminadas - Procedimento. Rio de Janeiro, RJ, 2013c. 4p.

BRASIL. Lei No 6,938, de 31 de agosto de 1981. Política Nacional do Meio Ambiente. Brasil, 1981. Disponível em: <http://www.planalto.gov.br/ccivil_03/Leis/L6938compilada.htm>. Acesso em 29 set. 2014.

BRASIL. Lei No 9.605, de 12 de fevereiro de 1998. Lei de Crimes Ambientais. Brasil, 1998. Disponível em: <http://www.planalto.gov.br/ccivil_03/leis/19605.htm〉. Acesso em: 29 set. 2014.

BRASIL. Constituição da República Federativa do Brasil: texto constitucional promulgado em 5 de outubro de 1988, com as alterações adotadas pelas Emendas Constitucionais nos 1/1992 a 68/2011, pelo Decreto Legislativo n 186/2008 e pelas Emendas Constitucionais de Revisão nos 1 a 6/1994. 35 ed. Brasil, 2012. 454p.

COMPANHIA AMBIENTAL DO ESTADO DE SÃO PAULO. Manual de Gerenciamento de Áreas Contaminadas. 2.ed. São Paulo, 2001. 389p.

COMPANHIA AMBIENTAL DO ESTADO DE SÃO PAULO. Diretoria de Controle e Licenciamento Ambiental. Relação de áreas Contaminadas e Reabilitadas no Estado de São Paulo. São Paulo, dezembro de 2013. Disponível em: 
<http://www.cetesb.sp.gov.br/userfiles/file/areas-contaminadas/2013/texto-explicativo.pdf>. Acesso em: 29 set. 2014.

COMPANHIA AMBIENTAL DO ESTADO DE SÃO PAULO. Glossário. São Paulo, 2014 Disponível em: 〈http://www.cetesb.sp.gov.br/institucional/institucional/70-glossario\#P>. Acesso em: 18 nov. 2014.

CONSELHO NACIONAL DO MEIO AMBIENTE. Resolução No 001, de 23 de janeiro de 1986. Dispõe sobre critérios básicos e diretrizes gerais para a avaliação de impacto ambiental. Brasil, 1986.

CONSELHO NACIONAL DO MEIO AMBIENTE. Resolução No 237, de 19 de dezembro de 1997. Dispõe sobre a revisão e complementação dos procedimentos e critérios utilizados para o licenciamento ambiental Brasil, 1997.

CONSELHO NACIONAL DO MEIO AMBIENTE. Resolução No 396, de 3 de abril de 2008. Dispõe sobre a classificação e diretrizes ambientais para o enquadramento das águas subterrâneas e dá outras providências. Brasil, 2008.

CONSELHO NACIONAL DO MEIO AMBIENTE. Resolução $\mathbf{N}^{\mathbf{0}} \mathbf{4 2 0}$, de 28 de dezembro de 2009. Dispõe sobre critérios e valores orientadores de qualidade do solo quanto à presença de substâncias químicas e estabelece diretrizes para o gerenciamento ambiental de áreas contaminadas por essas substâncias em decorrência de atividades antrópicas. Brasil, 2009.

ENVIRONMENTAL PROTECTION AGENCY. Valuing potential environmental liabilities for managerial decision-marking: a review of available techniques. Publication 742-R-96-003; Washington DC: EPA, 1996.

PEDROZO, M.F.M.; BARBOSA, E.M.; CORSEUIL, H.X.; SCHNEIDER, M.R.; LINHARES, M.M. Ecotoxicologia e Avaliação de Risco do Petróleo. Salvador, Bahia: CRA - Centro de Recursos Ambientais, 2002. 229 p.

SCHNEIDER, Márcio Roberto. Intemperismo de Fontes de Contaminação em Aquíferos Impactados por Derramamentos de Gasolina e Álcool e a Influência sobre o Risco à Saúde Humana. Florianópolis, 2005. 192p. Tese (Doutorado) - Universidade Federal de Santa Catarina. Centro Tecnológico. Departamento de Engenharia Sanitária e Ambiental. Programa de PósGraduação em Engenharia Ambiental.

SOARES, A.C; LEAL, J.E; AZEVEDO, I.R. Diagnóstico da rede de distribuição de derivados de petróleo no Brasil e sua representação em um SIG. XXIII Encontro Nacional de Engenharia de Produção - Outro Preto, Minas Gerais, outubro de 2003. Disponível em:

<http://www.abepro.org.br/biblioteca/ENEGEP2003_TR0112_0640.pdf>. Acesso em: 27 set. 2014. 
